\title{
The Utility of Vitamins in the Prevention of Type 2 Diabetes Mellitus and Its Complications: A Public Health Perspective
}

\author{
Alaa Badawi, Bibiana Garcia-Bailo, Paul Arora, Mohammed H. Al Thani, \\ Eman Sadoun, Mamdouh Farid and Ahmed El-Sohemy
}

Additional information is available at the end of the chapter

http://dx.doi.org/10.5772/47834

\section{Introduction}

Type 2 diabetes mellitus (T2DM) is currently considered as a global health problem where about six people die every minute from the disease worldwide. This rate will make T2DM one of the world's most prevalent causes of preventable mortality [1]. T2DM is caused by impaired glucose tolerance (IGT) as a result of insulin resistance and consequential islet $\beta$ cell exhaustion, with ensuing insulin deficiency [2]. In individuals with IGT, numerous genetic, host-related, and environmental factors contribute to the progression of insulin resistance to T2DM [3-7]. Obesity, however, is a major cause of insulin resistance [5] and can be complicated by metabolic dysregulation including hypertension and dyslipidemia [known collectively as the metabolic syndrome] which is a precursor of T2DM. The dyslipidemia involves high levels of triacylglycerides and circulating fatty acids originating from the diet or accelerated lipolysis in adipocytes. Direct exposure of muscle cells to these fatty acids impairs insulin-mediated glucose uptake and, therefore, may contribute to insulin resistance [8,9]. Within the last decade, a hypothesis was proposed to explain the pathogenesis of T2DM that connects the disease to a state of subclinical chronic inflammation $[10,11]$. Inflammation is a short-term adaptive response of the body elicited as a principle component of tissue repair to deal with injuries and microbial infections (e.g., cold, flu, etc.). It can be also elevated in chronic conditions such as peripheral neuropathy, chronic kidney disease and fatty liver. While the influence of fats is well known (see below), current thinking suggests that abnormal levels of chemokines released by the expanding adipose tissue in obesity activate monocytes and increase the secretion of pro-inflammatory adipokines. Such cytokines in turn enhance insulin resistance in adipose and other tissues, thereby increasing the risk for T2DM [12,13]. Together, lipid toxicity and low-grade 
inflammation appear to be major assaults on insulin sensitivity in insulin-responding tissues $[9,14,15]$.

Activation of innate immunity promotes various inflammatory reactions that provide the first line of defense the body invokes against microbial, chemical, and physical injury, leading to repair of damage, isolation of microbial infectious threats and restoration of tissue homeostasis [16,17]. Inherited variations in the degree of innate immune response may determine the lifetime risk of diseases upon exposure to adverse environmental stimuli [18]. Therefore, innate immune responses can be viewed as the outcome of interaction between genetic endowment and the environment [19].

This article was undertaken in an attempt to evaluate the current knowledge linking vitamin intake to attenuating inflammation, and thereby reducing the risk of T2DM and its complications.

\section{Micronutrients, T2DM and inflammation}

Factors that attenuate inflammation could provide an important public health tool to reduce the burden of diseases related to this pathway, such as obesity, T2DM and cardiovascular diseases, in the general population. The feasibility of modulating innate immunity-related inflammation as an approach for the prevention of T2DM is based on reports that evaluated the efficacy of anti-inflammatory pharmaceutical agents on disease manifestation and outcome $[12,20]$.

A therapeutic strategy for T2DM that would act primary on the inflammatory system has been proposed in the form of salicylates, an anti-inflammatory agent long known to have a hypoglycemic effect [21,22]. Nonsteroidal anti-inflammatory drugs (NSAIDs) and cyclooxygenase inhibitors are able to enhance glucose-induced insulin release, improve glucose tolerance, and increase the effect of insulin in patients with T2DM [15,23,24]. In humans, treatment with NSAIDs improved various biochemical indices associated with T2DM [25]. Although these observations support the notion that inflammation plays a pivotal role in T2DM, attenuating inflammation as a strategy for disease prevention in a public health setting will necessitate a substantially different perspective. In this case, a strategy that can be introduced into the general population with the least (if any) side effects and the maximal preventive outcome should be adopted. In this context, a nutritional intervention approach would be a desirable option.

Numerous nutritional factors can modify innate immune-related responses and, subsequently, modify the risk of a range of chronic conditions. With respect to T2DM, the consensus of available information suggests that micronutrient intake modulates the innate immune system [26] and can subsequently influence the predisposition to [and prevention of] disease [26-28]. By virtue of this observation, the hope is that the outcome of nutritional supplementation can be simply monitored via its modifying action on the levels of inflammatory biomarkers. Many micronutrients exhibit well-characterized antiinflammatory or immunomodulatory functions [25]. Vitamins (e.g., D, E, and C), certain fatty acids (e.g., omega-3 fatty acid) and trace elements (e.g., selenium, zinc, copper and 
iron) are known to improve the overall function of the immune system, prevent excessive expression and synthesis of inflammatory cytokines, and increase the 'oxidative burst' potential of macrophages [25]. Vitamin $C$ is the major water-soluble dietary antioxidant antiinflammatory factor, exerting its actions in the aqueous phase. In contrast, vitamins $\mathrm{E}$ and D are lipid-soluble and protect against inflammation in the lipid phase, e.g., adipocytes. Although acting primarily in different phases, these micronutrients can function together by regenerating each other in the reduced form [29]. Indeed, exploring the possibility that supplementation with selected micronutrients can attenuate obesity-related inflammation in order to delay the development of T2DM should be considered alongside existing public health practices to reduce the disease rising rates.

\section{Vitamin C}

Vitamin C (ascorbic acid or ascorbate), an essential nutrient, is a 6-carbon lactone and the primary hydrophilic antioxidant found in human plasma [30]. Circulating concentrations of ascorbate in blood are considered adequate if at least $28 \mu \mathrm{M}$, but they are considerably higher in most cells due to active transport. The daily recommended dietary allowance for vitamin $\mathrm{C}$ is $75 \mathrm{mg}$ for women and $90 \mathrm{mg}$ for men, with an additional $35 \mathrm{mg}$ for smokers due to the higher metabolic turnover of the vitamin in this group as compared to nonsmokers [31]. Ascorbate appears in the urine at intakes of roughly $60 \mathrm{mg} /$ day. However, the results of a depletion/repletion study in healthy young women showed that ascorbate plasma and white blood cell concentrations only saturate at intakes of $200 \mathrm{mg} /$ day or higher [32]. These results suggest that the current dietary recommendations may not provide tissue-saturating ascorbate concentrations [33]. Indeed, epidemiologic findings suggest that serum ascorbic acid deficiency may be relatively common. For example, a recent crosssectional survey of healthy young adults of the Toronto Nutrigenomics and Health (TNH) Study reported that 1 out 7 individuals is deficient in serum ascorbic acid [34].

Vitamin $\mathrm{C}$ has an important role in immune function and various oxidative and inflammatory processes, such as scavenging reactive oxygen species (ROS), preventing the initiation of chain reactions that lead to protein glycation [31;35] and protecting against lipid peroxidation [31, 36]. The oxidized products of vitamin C, ascorbyl radical and dehydroascorbic acid, are easily regenerated to ascorbic acid by glutathione, NADH or $\mathrm{NADPH}$ [31]. In addition, ascorbate can recycle vitamin $\mathrm{E}$ and glutathione back from their oxidized forms [31,33]. For this reason, there has been interest in determining whether vitamin $\mathrm{C}$ might be used as a therapeutic agent against the oxidative stress and subsequent inflammation associated with T2DM.

A variety of epidemiologic studies have assessed the effect of vitamin $C$ on biomarkers of oxidation, inflammation and/or T2DM risk [30, 37-42]. A large cross-sectional evaluation of healthy elderly men from the British Regional Heart Study reported that plasma vitamin C, dietary vitamin $C$ and fruit intake were inversely correlated with serum CRP and tissue plasminogen activator [tPA], a biomarker of endothelial disfunction [134]. However, only plasma vitamin C was inversely associated with fibrinogen levels [30]. Another crosssectional study of adolescents aged 13-17 found inverse associations between intakes of 
fruit, vegetables, legumes and vitamin $\mathrm{C}$ and urinary $\mathrm{F}_{2}$-isoprostane, CRP, and IL-6 [43]. A recent cross-sectional evaluation of healthy young adults from the TNH Study demonstrated that serum ascorbic acid deficiency is associated with elevated CRP and other factors related to the metabolic syndrome such as waist circumference, BMI and high blood pressure [34]. Finally, the European Prospective Investigation of Cancer (EPIC)-Norfolk Prospective Study examined the link between fruit and vegetable intake and plasma levels of vitamin C and risk of T2DM. During 12-year follow-up, 735 incident cases of diabetes were identified among nearly 21,000 participants [44]. A significant inverse association was found between plasma levels of vitamin $\mathrm{C}$ and risk of diabetes (OR=0.38, 95\% $\mathrm{CI}=0.28-0.52$ ). In the same study, a similar association was observed between fruit and vegetable intake and $\mathrm{T} 2 \mathrm{DM}$ risk $(\mathrm{OR}=0.78,95 \% \mathrm{CI}=0.60-1.00)$ [44].

Despite epidemiologic findings generally pointing towards an association between increased vitamin $C$ and reduced oxidation and inflammation, intervention trials assessing the effect of vitamin C supplementation on various markers of T2DM have yielded inconsistent results. One randomized, cross-over, double-blind intervention trial reported no improvement in fasting plasma glucose and no significant differences in levels of CRP, IL-6, IL-1 receptor agonist or oxidized LDL after supplementation with $3000 \mathrm{mg} /$ day of vitamin C for 2 weeks in a group of 20 T2DM patients, compared to baseline levels [45]. Chen and colleagues performed a randomized, controlled, double-blind intervention on a group of 32 diabetic subjects with inadequate levels of vitamin $\mathrm{C}$ and found no significant changes in either fasting glucose or fasting insulin after intake of $800 \mathrm{mg} /$ day of vitamin $C$ for 4 weeks [46].

On the other hand, Wang and colleagues showed that the red blood cell sorbitol/plasma glucose ratio was reduced after supplementation with $1000 \mathrm{mg} /$ day vitamin $C$ for 2 weeks in a group of eight diabetics, although no differences were found in fasting plasma glucose [47]. Since sorbitol is a product of the pro-oxidative polyol pathway, this observation may suggest an inhibition of the polyol pathway by vitamin $C$ among subjects with diabetes. Another study has shown that daily intake of ascorbic acid at $2000 \mathrm{mg} /$ day improved fasting plasma glucose, HbA1c, cholesterol levels and triglycerides in 56 diabetics [48]. In agreement, Paolisso et. al. found that $1000 \mathrm{mg}$ /day of vitamin C for 4 months improved LDL and total cholesterol, fasting plasma insulin and free radicals, although it did not affect triglycerides or HDL levels in a group of 40 diabetics [49].

Overall, it remains unclear whether vitamin $C$ intake has an effect on factors related to T2DM. Although the epidemiologic evidence suggests that vitamin $C$, whether as a supplement or as part of a diet rich in fruits and vegetables, beneficially affects inflammatory markers and disease risk, the results of intervention trials in T2DM are conflicting. Small sample sizes, genetic variation, short intervention duration, insufficient dosage and disease status of the assessed cohorts may account for the lack of effect and the inconsistent outcomes observed in intervention studies. However, it is possible also that the status of vitamin $C$ deficiency is a result of the oxidative and pro-inflammatory challenges associated with T2DM rather than a determinant of disease pathogenesis. Therefore, further research and long-term prospective studies are needed to elucidate the role of vitamin $\mathrm{C}$ as a modulator of inflammation and T2DM risk, and to evaluate its potential role as a preventive agent at a population level. 


\section{Vitamin E}

Vitamin E encompasses a group of 8 compounds, including $\alpha, \beta, \gamma$, and $\delta$ tocopherols and $\alpha$, $\beta, \gamma$, and $\delta$ tocotrienols, with differing biological activities. Each compound contains a hydroxyl-containing chromanol ring with a varying number and position of methyl groups between the $\alpha, \beta, \gamma$, and $\delta$ forms [29]. It is known to have a significant impact on improving a variety of immune functions [50]. Supplementation with vitamin E increases the rate of lymphocyte proliferation by enhancing the ability of $\mathrm{T}$ cells to undergo cell division cycles [51]. The effective anti-inflammatory action of vitamin $\mathrm{E}$ was substantiated from observations such as the increased expression of the IL-2 gene and IL-1 receptor antagonist and the decreased expression of IL-4 following vitamin E supplementation in animal models [50]. Furthermore, vitamin E reduced the serum levels of inflammatory factors such as IL-1 $\beta$, IL-6, TNF- $\alpha$, PAI-1, and CRP in T2DM patients [52, 53]. Furthermore, vitamin E downregulates NFผB [52], the principal mediator of inflammatory signaling cascade and its potent lipophilic antioxidant effect on internal and external cell membranes as well as plasma lipoproteins, notably LDL. Based on this latter characteristic, studies in both animal models and humans have demonstrated that vitamin $\mathrm{E}$ intake blocks LDL lipid peroxidation, prevents the oxidative stress linked to T2DM-associated abnormal metabolic patterns [hyperglycemia, dyslipidemia, and elevated levels of FFAs], and, subsequently, attenuates cytokine gene expression [50, 52, 56, 57]. Despite these findings, a recent study evaluated the effects of a combination of vitamin C (1000 mg/day) and vitamin E (400 IU/day) for four weeks on insulin sensitivity in untrained and trained healthy young men and concluded that such supplementation may preclude the exercise-induced amelioration of insulin resistance in humans [58]. This may relate to the source of vitamin E used, i.e., $\alpha-$, $\beta-, \gamma-$, or $\delta$-tocopherol [59].

Overall, the immunomodulatory, anti-inflammatory and anti-oxidative functions of vitamin E strongly support its possible application in designing effective prevention and/or treatment protocols for T2DM [25, 56]. Current practices for diabetes prevention in the general population include lifestyle change, dietary intervention and exercise. Vitamin E supplementation may further aid in T2DM prevention and control through its anti-oxidant, anti-inflammatory and immunomodulatory properties. It seems reasonable, therefore, to suggest supplementation with vitamin $\mathrm{E}$ together with lifestyle change may be combined into a single program to enhance the success and effectiveness of intervention. This strategy could be more efficient in reducing the low-grade inflammation associated with pre-clinical T2DM and, subsequently the disease burden, than when a single approach is considered. Moreover, such a combined strategy can be introduced in general practice settings and in a population-based fashion with low expenditure and minimal side effects.

\section{Vitamin D}

The role of vitamin D in calcium and phosphorus homeostasis and bone metabolism is well understood. However, more recently vitamin $\mathrm{D}$ and calcium homeostasis have also been linked to a number of conditions, such as neuromuscular function, cancer, and a wide range of chronic diseases, including autoimmune diseases, atherosclerosis, obesity, cardiovascular 
diseases, diabetes and associated conditions such as the metabolic syndrome and insulin resistance [25, 60-63]. In T2DM, the role of vitamin D was suggested from the presence of vitamin D receptors (VDR) in the pancreatic $\beta$-islet cells [63]. In these cells, the biologically active metabolite of vitamin D (i.e., 1,25-dihydroxy-vitamin D; 1,25[OH]D) [64] enhances insulin production and secretion via its action on the VDR [63]. Indeed, the presence of vitamin D binding protein (DBP), a major predictor of serum levels of $25(\mathrm{OH}) \mathrm{D}$ and response to vitamin D supplementation [65, 66], and VDR initiated several studies demonstrating a relationship between single nucleotide polymorphisms (SNPs) in the genes regulating VDR and $D B P$ and glucose intolerance and insulin secretion [67-69]. This further supports a role for vitamin D in T2DM and may explain the reduced overall risk of the disease in subjects who ingest $>800 \mathrm{IU} / \mathrm{d}$ of vitamin $\mathrm{D}[61,70]$. However, an alternative, and perhaps related, explanation was recently proposed for the role of vitamin D in T2DM prevention based on its potent immunomodulatory functions [71-73]. 1,25(OH)D modulates the production of the immunostimulatory IL-12 and the immunosuppressive IL-10 [74] and VDRs are present in most types of immune cells [75]. In this respect, supplementation with vitamin D [76] or its bioactive form, 1,25(OH)D [64], improved insulin sensitivity by preventing the excessive synthesis of inflammatory cytokines. This effect of vitamin D on cytokine synthesis is due to its interaction with vitamin D response elements (VDRE) present in the promoter region of cytokine-encoding genes. This interaction downregulates the transcriptional activities of cytokine genes and attenuates the synthesis of the corresponding proteins [76]. Vitamin D also deactivates $\mathrm{NF} \kappa \mathrm{B}$, which transcriptionally upregulates the pro-inflammatory cytokine-encoding genes [77]. Downregulating the expression of $\mathrm{NF \kappa B}$ and downstream cytokine genes inhibits $\beta$-cell apoptosis and promotes their survival [76].

As reviewed by Pittas et al [78], a number of cross-sectional studies in both healthy and diabetic cohorts have shown an inverse association between serum $25(\mathrm{OH}) \mathrm{D}$ and glycemic status measures such as fasting plasma glucose, oral glucose tolerance tests, hemoglobin A1c (HbA1c), and insulin resistance as measured by the homeostatic model assessment (HOMAR), as well as the metabolic syndrome [79-84]. For example, data from the National Health and Nutrition Examination Survey (NHANES) showed an inverse, dose-dependent association between serum $25(\mathrm{OH}) \mathrm{D}$ and diabetes prevalence in non-Hispanic whites and Mexican Americans, but not in non-Hispanic blacks [81,84]. The same inverse trend was observed between serum 25(OH)D and insulin resistance as measured by HOMA-R, but there was no correlation between serum levels of vitamin $\mathrm{D}$ and $\beta$-cell function, as measured by HOMA- $\beta[81,84]$. Data from the same cohort also showed an inverse association between $25(\mathrm{OH}) \mathrm{D}$ and prevalence of the metabolic syndrome [81].

In prospective studies, dietary vitamin $\mathrm{D}$ intake has been associated with incidence of T2DM. For example, data from the Women's Health Study showed that, among middleaged and older women, taking $>511$ IU/day of vitamin D reduced the risk of developing T2DM, as compared to ingesting 159 IU/day [85]. Furthermore, data from the Nurses Health Study also found a significant inverse correlation between total vitamin D intake and T2DM risk, even after adjusting for BMI, age, and non-dietary covariates [70]. Intervention studies have shown conflicting results about the effect of vitamin D on T2DM incidence. One study reported that supplementation with $1,25[\mathrm{OH}]_{2} \mathrm{D}_{3}$ for 1 week did not affect fasting glucose or 
insulin sensitivity in 18 young healthy men [86]. Another study found that, among 14 T2DM patients, supplementing with $80 \mathrm{IU} /$ day of $1 \alpha$-OHD 3 ameliorated insulin secretion but did not improve glucose tolerance after a $75 \mathrm{~g}$ oral load [87]. Yet another study showed that, among 65 middle-aged men who had IGT or mild T2DM and adequate serum vitamin D levels at baseline, supplementation with $30 \mathrm{IU} /$ day of $1-\alpha-\mathrm{OHD}_{3}$ for 3 months affected neither fasting nor stimulated glucose tolerance [88]. However, in a cross-over design, 20 diabetics with inadequate vitamin $\mathrm{D}$ serum levels who were given $40 \mathrm{IU} /$ day of 1,25-OHD for 4 days had improved insulin secretion, but showed no changes in fasting or stimulated glucose or insulin concentrations [89]. Although the short duration of this cross-over trial may account for the lack of a significant overall effect, the results suggest that improving vitamin D status can modulate factors associated with the development and progression of T2DM.

The data from a 2-year-long trial designed to assess the effects of vitamin $\mathrm{D}_{3}$ or $1-\alpha-\mathrm{OHD}_{3}$ supplementation on bone health in non-diabetic postmenopausal women were analyzed $a$ posteriori and found no significant effect on fasting glucose levels [90]. A post-hoc analysis of data from a 3-year trial for bone health showed that daily supplementation with $700 \mathrm{IU}$ of vitamin $\mathrm{D}_{3}$ and $500 \mathrm{mg}$ of calcium citrate malate did not change blood glucose levels or insulin resistance in elderly adults with normal glucose tolerance. These measures, however, were significantly improved in subjects with IGT at baseline [91]. In this trial the effect of fasting glucose levels in the high-risk group (i.e., IGT) was similar to that observed in the Diabetes Prevention Program after an intensive lifestyle intervention or metformin treatment [92]. Taken together, the available information warrants exploring the possibility that vitamin D (alone or in combination with calcium) can be employed in developing population-based strategies for T2DM prevention and control.

\section{6. $\beta$-carotene and lycopene}

As previously stated, oxidative stress is involved in the development and complications of T2DM [60]. Patients with T2DM exhibit a reduced antioxidative defence, which negatively correlates with glucose levels and duration of the disease [93]. In diabetic subjects, the lack of metabolic homeostasis, the increased plasma ROS generation and the decreased efficiency of inhibitory and scavenger systems [60], all can that result in a status of oxidative stress that can have an etiological role in T2DM complications, e.g., retinopathy, chronic kidney disease, and cardiovascular diseases [94]. The synthesis of ROS was proposed to be primarily due to hyperglycaemia [95] resulting in stimulation of the polyol pathway, formation of advanced glycosylation endproducts, and subsequent formation of ROS. Hyperinsulinaemia, insulin resistance and inflammation, may all play a role in the synthesis of ROS in pre-diabetic and diabetic patients [60].

As we reviewed recently, the risk of T2DM can be mitigated by increased antioxidants intake [60]. Intake of $\alpha$ - and $\beta$-carotene and lycopene has been shown to improve glucose metabolism in subjects at high risk of T2DM [96], and glucose metabolism has been associated with oxidative stress [95]. Indeed, diabetic patients have shown a predominantly elevated levels of lipid peroxidation ( $\mathrm{F}_{2}$-isoprostanes) [97]. In vivo lipid peroxidation, measured as $\mathrm{F}_{2}$-isoprostanes, apprears to be influenced by the consumption of dietary 
components such as antioxidants. It is therefore critical to examine the dietary effects of $\alpha$ and $\beta$-carotene and lycopeneon lipid peroxidation in patients with T2DM. The relationship between plasma levels of antioxidants and markers of oxidative stress and inflammation have been described in healthy population $[58,98]$ and is yet to be identified in diabetic subjects. This will allow us to better define the role of $\alpha$ - and $\beta$-carotene and lycopene in attenuating inflammation and modulating the oxidative stress during the course of T2DM development and progression.

\section{T2DM complications: Cardiometabolic disease}

It is well-established that T2DM is a risk factor for cardiometabolic diseases. Studies from our group demonstrated a relationship between T2DM and its risk factors and cardiometabolic disease markers [98,99]. We observed an apparent profile of metabolic phenotypes and inflammatory biomarkers, known to be related to the cardiometabolic disease risk, that emerges with the susceptibility to T2DM. These findings allowed us to establish a composite metabolic trait that lead to the development of improved strategies for early risk prediction and intervention.

In the same study population, we further demonstrated an association between plasma vitamin D level and T2DM risk, e.g., insulin resistance [100]. We found that the likelihood that T2DM develops and results in related complications is further increased as plasma vitamin D levels decrease. These studies highlights the possibility that micronutrient supplementation can be employed in the prevention of various T2Dm complications including cardimetabolic diseases. Moreover, there is a need to develop adequately powered randomized controlled clinical trials to evaluate the value of replenishment of vitamin D on T2DM and the related conditions, e.g., obesity, insulin resistance and cardiovascular diseases, as an approach for an effective population based strategy for disease prevention.

\section{Public health prespectives}

Introducing novel and effective prevention strategies in a public health setting necessitates considering approaches with the least [if any] side effects and the maximal preventive efficacy and outcome. Furthermore, the heterogeneity of the general Western population in terms of culture, location and resources renders creating a unified intervention program a formidable endeavour. In this context, applying nutritional intervention as an approach to attenuate inflammation and oxidative stress would be a feasible public health strategy for the T2DM. A conceptual model need to be implemented to improve the availability and accessibility of nutritious food as a factor that can be integrated into a comprehensive public health intervention strategy aimed at T2DM prevention.

Combining micronutrients supplementation or encouraging the consumption of nutritious diet should be explored in pre-diabetic subjects and the outcome should be compared to the effect(s) of changing current practices, such as lifestyle change, dietary intervention and exercise. The effectiveness of lifestyle-change intervention programmes for pre-diabetes also shows a promising effect on the reduction of overall incidence of T2DM or its complications, 
and it can be implemented in general clinical practice [95]. A lifestyle-change programme including increased exercise and diet change (either by reduction in glycemic load or reduced-fat diet) demonstrated a significant difference between control and intervention groups in markers for risk of progression to T2DM including weight, BMI, and waist circumference [101]. In general, current approaches for the prevention of T2DM have been shown to be effective in delaying or preventing the progression from pre-diabetes to diabetes [102]. In patients with insulin resistance, these practices are known to improve insulin sensitivity and the overall predisposition to T2DM [103]. On the other hand, increasing intake of vitamin D to greater than $800 \mathrm{IU}$ daily along with $1200 \mathrm{mg}$ of calcium was reported to reduce the risk of developing T2DM by 33\% [78]. In agreement, healthy older adults with impaired fasting glucose showed significant improvement in attenuating the glycemic response and insulin resistance when they increased the vitamin D to $700 \mathrm{IU} / \mathrm{d}$ and calcium to $500 \mathrm{mg} / \mathrm{d}$ for 3 yrs [70]. It seems reasonable, therefore, to suggest that the two preventive approaches for T2DM, i.e., micronutrient supplementation and lifestyle change, may be combined into a single successful intervention programme. This strategy may be more efficient in reducing the burden of the disease in the general population and in vulnerable subpopulations than when a single approach is proposed. Moreover, such a combined approach may be introduced into the general practice setting and to the general population with low expenditure and minimal side effects $[25,60]$.

Overall, the current state of knowledge warrants further study into the extent to which micronutrients can modify the association between markers of inflammation and oxidative stress and early stages of T2DM. There is evidence supporting the idea that vitamin supplementation can modify the genotype-phenotype association within the innate immune response (i.e., the pro-inflammatory and inflammatory markers), and that it has an ameliorating effect on oxidative stress and the subsequent inflammatory signalling. This proposition may provide the mechanism by which nutritional factors prevent or delay disease development and can be introduced into the general population, as well as susceptible subpopulations. In relation to the current preventive approaches for T2DM, e.g., lifestyle changes, exercise, and dietary intervention, exploring the efficacy of micronutrient supplementation on attenuating oxidative stress, the innate immune response and the ensuing inflammation and evaluating the outcome of this strategy on T2DM incidence may be assessed through a series of prospective population-based studies, first, to determine the feasibility and effectiveness of this protocol; second, to validate and evaluate this strategy and ensure replication of results; and, third, to monitor the outcome to quantify the overall preventive response in comparison with the current approaches.

\section{Author details}

Alaa Badawi*

Office for Biotechnology, Genomics and Population Health, Public Health Agency of Canada, Toronto, ON, Canada

${ }^{*}$ Corresponding Author 
Bibiana Garcia-Bailo

Office for Biotechnology, Genomics and Population Health, Public Health Agency of Canada, Toronto, ON, Canada

Department of Nutritional Sciences, Faculty of Medicine, University of Toronto, ON, Canada

Paul Arora

Office for Biotechnology, Genomics and Population Health, Public Health Agency of Canada, Toronto, ON, Canada

Dalla Lana School of Public Health, University of Toronto, Toronto, ON, Canada

Mohammed H. Al Thani and Eman Sadoun

Supreme Council of Health, Doha, Qatar

Mamdouh Farid

Queen Medical research Office, Doha, Qatar

Ahmed El-Sohemy

Department of Nutritional Sciences, Faculty of Medicine, University of Toronto, ON, Canada

\section{Acknowledgement}

This work is supported by the Public Health Agency of Canada.

\section{References}

[1] Wild S, Rolic C, Green A. Global prevalence of diabetes: Estimates for the year 2000 and projection for 2030. Diabetes Care. 2004;37:1047-1053.

[2] Stumvoll M, Goldstein B, van Haeften T. Type 2 diabetes: principles of pathogenesis and therapy. Lancet. 2005;365:1333-1346.

[3] Zimmet P, Alberti KG, Shaw J. Global and societal implications of the diabetes epidemic. Nature. 2001;414:782-787.

[4] Alberti KG. Treating type 2 diabetes-today's targets, tomorrow's goals. Diabetes Obesity Metabolism. 2001;3(Suppl 1):S3-S10.

[5] Dandona P, Aljada A, Bandyopadhyay A. Inflammation: the link between insulin resistance, obesity and diabetes. Trends Immunology. 2004;25:4-7.

[6] Dandona P, Aljada A. A rational approach to pathogenesis and treatment of type 2 diabetes mellitus, insulin resistance, inflammation, and atherosclerosis. American Journal Cardiology. 2002;90:27G-33G.

[7] Dandona P, Aljada A, Chaudhuri A, Bandyopadhyay A. The potential influence of inflammation and insulin resistance on the pathogenesis and treatment of atherosclerosis-related complications in type 2 diabetes. Journal Clinical Endocrinology Metabolism. 2003;88:2422-2429.

[8] Dimopoulos N, Watson M, Sakamoto K, Hundal HS. Differential effects of palmitate and palmitoleate on insulin action and glucose utilization in raty L6 skeletal muscle cells. Biochemistry Journal. 2006;399:473-481. 
[9] Bilan PJ, Samokhvalov V, Koshkina A, Schertzer JD, Samaan MC, Klip A. Direct and macrophage-mediated actions of fatty acids causing insulin resistance in muscle cells. Archive Physiology Biochemistry. 2009;115:176-190.

[10] Pickup JC, Crook MA. Is type II diabetes mellitus a disease of the innate immune system? Diabetologia. 1998;41:1241-1248.

[11] Pickup JC, Matttock MB, Chusney GD, Burt D. NIDDM as a disease of the innate immune system: association of acute phase reactants and interleukin- 6 with metabolic syndrome X. Diabetologia. 1997;40:1286-1292.

[12] King GL. The role of inflammatory cytokines in diabetes and its complications. Journal Periodontology. 2008;79:1527-1534.

[13] Larsen GL, Henson PM. Mediators of inflammation. Annals Review Immunology. 1983;1:335-359.

[14] Hotamisligil GS, Shargill NS, Spiegelman BM. Adipose expression of tumor necrosis factor-alpha: direct role in obesity-linked insulin resistance. Science. 1993;259:87-91.

[15] Hotamisligil GS. Inflammation and metabolic disorders. Nature. 2006;444:860-867.

[16] Beutler B. Innate immunity: an overview. Molecular Immunology. 2004;40:845-859.

[17] Takeda K, Akira S. TLR signaling pathways. Seminars Immunology. 2004;16:3-9.

[18] Le Souëf PN. Gene-environmental interaction in the development of atopic asthma: new developments. Current Opinion Allergy Clinical Immunology. 2009;9:123-127.

[19] Fernandez-Real JM, Pickup JC. Innate immunity, insulin resistance and type 2 diabetes. Trends Endocrinology Metabolism. 2007; 19:10-16.

[20] Liu G, Rondinone CM. JNK: bridging the insulin signaling and inflammatory pathway. Curr Opin Investig Drugs. 2005; 6:979-987.

[21] Robertson RP. Prostaglandins as modulators of pancreatic islet function. Diabetes. 1979;28:942-948.

[22] Robertson RP. Arachidonic acid metabolism, the endocrine pancreas, and diabetes mellitus. Pharmacology Therapy. 1984;24:91-106.

[23] Wellen KE, Hotamisligil GS. Inflammation, stress, and diabetes. Journal Clinical Investigation. 2005;115:1111-1119.

[24] Hundal RS, Peterson KF, Mayerson AB, et al. Mechanism by which high-dose aspirin improves glucose metabolism in type 2 diabetes. Journal Clinical Investigation. 2002;109:1321-1326.

[25] Badawi, A., Klip, A., Haddad, P., Cole, D.E.C., Bailo, B.G., El-Sohemy, A., and Karmali, M. Type 2 diabetes mellitus and inflammation: Prospects for biomarkers of risk and nutritional intervention. Diabetes Metabolic Syndrome Obesity. 2010;3:173-186.

[26] Maggini S, Wintergerst ES, Beveridge S, Hornig DH. Selected vitamins and trace elements support immune function by strengthening epithelial barriers and cellular and humoral immune responses. British Journal Nutrition 2007;98(Suppl 1):S29-S35.

[27] Pittas AG, Lau J, Hu FB, Dawson-Hughes B. Review: The role of vitamin D and calcium in type 2 diabetes. A systematic review and meta-analysis. Journal Clinical Endocrinology Metabolism. 2007;92:2017-2029.

[28] Pittas AG, Dawson-Hughes B, Li T, et al. Vitamin D and calcium intake in relation to type 2 diabetes in women. Diabetes Care. 2006;29:650-656. 
[29] Da Costa, L.A., García-Bailo, B., Badawi, A., and El-Sohemy, A. Genetic determinants of dietary antioxidant status. In: Bouchard, C. and Ordovas, J.M. [eds.]. Recent Advances in Nutrigenetics and Nutrigenomics. Elsevier, New York, NY. 2012, in press.

[30] Wannamethee SG, Lowe GD, Rumley A, Bruckdorfer KR, Whincup PH. Associations of vitamin C status, fruit and vegetable intakes, and markers of inflammation and hemostasis. American Journal Clinical Nutrition 2006;83:567-574.

[31] Calder PC, Albers R, Antoine JM, Blum S, Bourdet-Sicard R, Ferns GA, Folkerts G, Friedmann PS, Frost GS, Guarner F, Lovik M, Macfarlane S, Meyer PD, M'Rabet L, Serafini $\mathrm{M}$, et al. Inflammatory disease processes and interactions with nutrition. British Journal Nutrition 2009;101 (Suppl 1):S1-S45.

[32] Levine M, Wang Y, Padayatty SJ, Morrow J. A new recommended dietary allowance of vitamin $C$ for healthy young women. Proceedings National Acadamy Science USA. 2001; 98:9842-9846.

[33] Aguirre R, May JM. Inflammation in the vascular bed: importance of vitamin C. Pharmacolocial Therapy. 2008;119:96-103.

[34] Cahill L, Corey PN, El-Sohemy A. Vitamin C deficiency in a population of young Canadian adults. American Journal Epidemiology. 2009;170:464-471.

[35] Bartlett HE, Eperjesi F. Nutritional supplementation for type 2 diabetes: a systematic review. Ophthalmic Physiology Opt. 2008; 28:503-523.

[36] Young IS, Tate S, Lightbody JH, McMaster D, Trimble ER. The effects of desferrioxamine and ascorbate on oxidative stress in the streptozotocin diabetic rat. Free Radical Biology Medicine 1995;18:833-840.

[37] Ford ES, Liu S, Mannino DM, Giles WH, Smith SJ. C-reactive protein concentration and concentrations of blood vitamins, carotenoids, and selenium among United States adults. European Journal Clinical Nutrition 2003; 57:1157-1163.

[38] Hamer M, Chida Y. Intake of fruit, vegetables, and antioxidants and risk of type 2 diabetes: systematic review and meta-analysis. Journal Hypertension 2007;25:2361-2369.

[39] Woodward M, Lowe GD, Rumley A, Tunstall-Pedoe H, Philippou H, Lane DA, Morrison CE. Epidemiology of coagulation factors, inhibitors and activation markers: The Third Glasgow MONICA Survey. II. Relationships to cardiovascular risk factors and prevalent cardiovascular disease. British Journal Haematology. 1997;97:785-797.

[40] Woodward M, Rumley A, Tunstall-Pedoe H, Lowe GD. Associations of blood rheology and interleukin- 6 with cardiovascular risk factors and prevalent cardiovascular disease. British Journal Haematology. 1999; 104:246-257.

[41] Woodward M, Rumley A, Lowe GD, Tunstall-Pedoe H. C-reactive protein: associations with haematological variables, cardiovascular risk factors and prevalent cardiovascular disease. British Journal Haematology 2003;122:135-141.

[42] Gao X, Bermudez OI, Tucker KL. Plasma C-reactive protein and homocysteine concentrations are related to frequent fruit and vegetable intake in Hispanic and nonHispanic white elders. Journal Nutrition. 2004;134:913-918.

[43] Holt EM, Steffen LM, Moran A, Basu S, Steinberger J, Ross JA, Hong CP, Sinaiko AR. Fruit and vegetable consumption and its relation to markers of inflammation and 
oxidative stress in adolescents. Journal American Dietetics Association 2009;109:414421.

[44] Harding AH, Wareham NJ, Bingham SA, Khaw K, Luben R, Welch A, Forouhi NG. Plasma vitamin $\mathrm{C}$ level, fruit and vegetable consumption, and the risk of new-onset type 2 diabetes mellitus: the European prospective investigation of cancer--Norfolk prospective study. Archives Internal Medicine. 2008; 168:1493-1499.

[45] Lu, Q, Bjorkhem,I, Wretlind,B, Diczfalusy,U, Henriksson,P, Freyschuss,A: Effect of ascorbic acid on microcirculation in patients with Type II diabetes: a randomized placebo-controlled cross-over study. Clinical Science. 2005;108:507-513.

[46] Chen H, Karne RJ, Hall G, Campia U, Panza JA, Cannon RO, III, Wang Y, Katz A, Levine M, Quon MJ. High-dose oral vitamin C partially replenishes vitamin C levels in patients with Type 2 diabetes and low vitamin $C$ levels but does not improve endothelial dysfunction or insulin resistance. American Journal Physiology Heart Circulation Physiology. 2006; 290:H137-H145.

[47] Wang H, Zhang ZB, Wen RR, Chen JW. Experimental and clinical studies on the reduction of erythrocyte sorbitol-glucose ratios by ascorbic acid in diabetes mellitus. Diabetes Research Clinical Practice 1995; 28:1-8.

[48] Eriksson J, Kohvakka A. Magnesium and ascorbic acid supplementation in diabetes mellitus. Annals Nutrition Metabolism. 1995;39:217-223.

[49] Paolisso G, Balbi V, Volpe C, Varricchio G, Gambardella A, Saccomanno F, Ammendola S, Varricchio M, D'Onofrio F. Metabolic benefits deriving from chronic vitamin C supplementation in aged non-insulin dependent diabetics. Journal American College Nutrition. 1995;14:387-392.

[50] Han SN, Adolfsson O, Lee CK, Prolla TA, Ordovas J, Meydani SN. Vitamin E and gene expression in immune cells. Annals NY Academy Science. 2004;1031:96-101.

[51] Adolfsson O, Huber BT, Meydani SN. Vitamin E-enhanced IL-2 production in old mice: naive but not memory $\mathrm{T}$ cells show increased cell division cycling and IL-2 -producing capacity. Journal Immunology. 2001;167:3809-3817.

[52] Singh U, Jialal I. Anti-inflammatory effects of $\alpha$-tocopherol. Annals NY Academy Science. 2004;1031:195-203.

[53] Devaraj JS, Jialal I. Alpha-tocopherol decreases interleukin-1 beta release from activated human monocytes by inhibition of 5-lipoxygenase. Arteriosclerosis Thrombosis Vascular Biology. 1999;19:1125-1133.

[54] Scott JA, King GL. Oxidative stress and antioxidant treatment in diabetes. Annals NY Academy Science. 2004;1031:204-213.

[55] Thomas SR, Stocker R. Molecular action of vitamin E in lipoprotein oxidation: Implications for athrosclerosis. Free Radical Biology Medicine. 2000;28:1795-1805.

[56] Ristow M, Zarse K, Oberbach A, et al. Antioxidants prevent healthpromoting effects of physical exercise in humans. Proceeding National Academy Science USA. 2009;106:8665-8670.

[57] Buijsee B, Feskens EJM, Kwape L, Kok FJ, Kormhout D. Both alphaand beta-carotene, but not tocopherols and vitamin $\mathrm{C}$, are inversely related to 15-year cardiovascular mortality in Dutch elderly men. Journal Nutrition. 2008;138:344-350. 
[58] Garcia-Bailo, B., El-Sohemy, A., Haddad, P., Arora, P., BenZaied, F., Karmali, M. and Badawi, A. Vitamins D, C and $\mathrm{E}$ in the prevention of type II diabetes mellitus: modulation of inflammation and oxidative stress. Biologics, 2011;5:7-19.

[59] Pittas AG, Lau J, Hu FB, Dawson-Hughes B. Review: The role of vitamin D and calcium in type 2 diabetes. A systematic review and meta-analysis. Journal Clinical Endocriology Metabolism 2007; 92:2017-2029.

[60] Botella-Carretero JI, Alvarez-Blasco F, Villafruela JJ, Balsa JA, Vazquez C, EscobarMorreale HF. Vitamin D deficiency is associated with the metabolic syndrome in morbid obesity. Clinical Nutrition. 2004;26:573-580.

[61] Teegarden D, Donkin SS. Vitamin D: emerging new roles in insulin sensitivity. Nutrition Research Reviews, 2009; 22:82-92.

[62] Holick MF. Diabetes and the vitamin D connection. Current Diabetes Reports 2008; 8:393-398.

[63] Maggini S, Wintergerst ES, Beveridge S, Hornig DH. Selected vitamins and trace elements support immune function by strengthening epithelial barriers and cellular and humoral immune responses. British Journal Nutrition. 2007;98(Suppl 1):S29-S35.

[64] Anan F, Takahashi N, Nakagawa M, Ooie T, Saikawa T, Yoshimatsu H. High-sensitivity C-reactive protein is associated with insulin resistance and cardiovascular autonomic dysfunction in type 2 diabetic patients. Metabolism 2005;54:552-558.

[65] Fu L, Yun F, Oczak M, Wong BY, Vieth R, Cole DE. Common genetic variants of the vitamin $\mathrm{D}$ binding protein (DBP) predict differences in response of serum 25hydroxyvitamin D $(25(\mathrm{OH}) \mathrm{D})$ to vitamin D supplementation. Clinical Biochemistry. 2009;42:1174-1177.

[66] Szathmary EJ. The effect of Gc genotype on fasting insulin level in Dogrib Indians. Human Genetics. 1987;75:368-372.

[67] Hirai M, Suzuki S, Hinokio Y, Hirai A, Chiba M, Akai H, Suzuki C, Toyota T. Variations in vitamin D-binding protein (group-specific component protein) are associated with fasting plasma insulin levels in Japanese with normal glucose tolerance. Journal Clinical Endocrinology Metabolism. 2000;85:1951-1953.

[68] Baier LJ, Dobberfuhl AM, Pratley RE, Hanson RL, Bogardus C. Variations in the vitamin D-binding protein (Gc locus) are associated with oral glucose tolerance in nondiabetic Pima Indians. Journal Clinical Endocrinology Metabolism. 1998;83:29932996.

[69] Pittas AG, Dawson-Hughes B, Li T, Van Dam RM, Willett WC, Manson JE, Hu FB. Vitamin $\mathrm{D}$ and calcium intake in relation to type 2 diabetes in women. Diabetes Care. 2006;29:650-656.

[70] Hayes CE, Nashold FE, Spach KM, Pedersen LB. The immunological functions of the vitamin D endocrine system. Cellular Molecular Biology. 2003; 49:277-300.

[71] Griffin MD, Xing N, Kumar R. Vitamin D and its analogs as regulators of immune activities and antigen presentation. Annual Reviews Nutrition. 2003;23:117-145.

[72] Cantorna MT, Zhu Y, Froicu M, Wittke A. Vitamin D status, 1,25-dihydroxy- vitamin D3, and the immune system. American Journal Clinical Nutrition. 2004;80:1717S-1720S. 
[73] DeLuca HF, Cantorna MT. Vitamin D: its role and uses in immunology. FASEB Journal. 2001;15:2579-2585.

[74] Veldman CM, Cantorna MT, DeLuca HF. Expression of 1,25-dihydroxyvitamin D3 receptor in the immune system. Archive Biochemistry Biophysics. 2000;374:338.

[75] Riachy R, Vandewalle B, Kerr CJ, Moerman E, Sacchetti P, Lukowiak B, Gmyr V, Bouckenooghe T, Dubois M, Pattou F. 1,25-dihydroxyvitamin D3 protects RINm5F and human islet cells against cytokine-induced apoptosis: implication of the antiapoptotic protein A20. Endocrinology. 2002;143:4809-4819.

[76] van Etten E, Mathieu C. Immunoregulation by 1,25-dihydroxyvitamin D3: basic concepts. Journal Steroides Biochemistry Molecular Biology. 2005;97:93-101.

[77] Pittas AG, Lau J, Hu FB, Dawson-Hughes B. Review: The role of vitamin D and calcium in type 2 diabetes. A systematic review and meta-analysis. Journal Clinical Endocriology Metabolism. 2007;92:2017-2029.

[78] Mokdad AH, Bowman BA, Ford ES, Vinicoor F, Marks JS, Koplan JP. The continuing epidemics of obesity and diabetes in the United States. Journal American Medical Association. 2001;286:1195-1200.

[79] Chiu KC, Chu A, Go VL, Saad MF. Hypovitaminosis D is associated with insulin resistance and beta cell dysfunction. American Journal Clinical Nutrition. 2004;79:820825.

[80] Ford ES, Ajani UA, McGuire LC, Liu S. Concentrations of serum vitamin D and the metabolic syndrome among U.S. adults. Diabetes Care. 2005;28:1228-1230.

[81] Hypponen E, Power C. Vitamin D status and glucose homeostasis in the 1958 British birth cohort: the role of obesity. Diabetes Care. 2006;29:2244-2246.

[82] Need AG, O'Loughlin PD, Horowitz M, Nordin BE. Relationship between fasting serum glucose, age, body mass index and serum 25 hydroxyvitamin D in postmenopausal women. Clinical Endocrinology. 2005;62:738-741.

[83] Scragg R, Sowers M, Bell C. Serum 25-hydroxyvitamin D, diabetes, and ethnicity in the Third National Health and Nutrition Examination Survey. Diabetes Care. 2004;27:2813-2818.

[84] Liu S, Song Y, Ford ES, Manson JE, Buring JE, Ridker PM. Dietary calcium, vitamin D, and the prevalence of metabolic syndrome in middle-aged and older U.S. women. Diabetes Care, 2005;28:2926-2932.

[85] Fliser D, Stefanski A, Franek E, Fode P, Gudarzi A, Ritz E. No effect of calcitriol on insulin-mediated glucose uptake in healthy subjects. European Journal Clinical Investigation. 1997;27:629-633.

[86] Inomata S, Kadowaki S, Yamatani T, Fukase M, Fujita T. Effect of 1 alpha (OH)-vitamin D3 on insulin secretion in diabetes mellitus. Bone Mineral 1986;1:187-192.

[87] Ljunghall S, Lind L, Lithell H, Skarfors E, Selinus I, Sorensen OH, Wide L. Treatment with one-alpha-hydroxycholecalciferol in middle-aged men with impaired glucose tolerance--a prospective randomized double-blind study. Acta Medica Scandnavia. 1987;222:361-367.

[88] Orwoll E, Riddle M, Prince M. Effects of vitamin D on insulin and glucagon secretion in non-insulin-dependent diabetes mellitus. American Journal Clinical Nutrition. 1994;59:1083-1087. 
[89] Nilas L, Christiansen C. Treatment with vitamin D or its analogues does not change body weight or blood glucose level in postmenopausal women. Intnational Journal Obesity. 1984;8:407-411.

[90] Pittas AG, Harris SS, Stark PC, Dawson-Hughes B. The effects of calcium and vitamin D supplementation on blood glucose and markers of inflammation in nondiabetic adults. Diabetes Care 2007; 30:980-986.

[91] Knowler WC, Barrett-Connor E, Fowler SE, Hamman RF, Lachin JM, Walker EA, Nathan DM. Reduction in the incidence of type 2 diabetes with lifestyle intervention or metformin. New England Journal Medicine. 2002;346:393-403.

[92] Colak E, Majkic-Singh N, Stankovic S, Sreckovic-Dimitrijevic V, Djordjevic PB, Lalic K, Lalic N. Parameters of antioxidative defense in type 2 diabetic patients with cardiovascular complications. Annals Medicine. 2005;37:613-620.

[93] Baynes JW. Role of oxidative stress in development of complications in diabetes. Diabetes. 1991;40:405-412.

[94] Ceriello A. Acute hyperglycaemia and oxidative stress generation. Diabet Med. 1997;14:45-49.

[95] Ylönen K, Alfthan G, Groop L, Saloranta C, Aro A, Virtanen SM. Dietary intakes and plasma concentrations of carotenoids and tocopherols in relation to glucose metabolism in subjects at high risk of type 2 diabetes: the Botnia Dietary Study. American Journal Clinical Nutrition. 2003;77:1434-1441.

[96] Helmersson J, Vessby B, Larsson A, Basu S. Association of type 2 diabetes with cyclooxygenase-mediated inflammation and oxidative stress in an elderly population. Circulation. 2004;109:1729-1734.

[97] Block G, Dietrich M, Norkus E, Jensen C, Benowitz NL, Packer L, et al. Intraindividual variability of plasma antioxidants, markers of oxidative stress, C-reactive protein, cotinine, and other biomarkers. Epidemiology. 2006;17:404-412.

[98] Brenner DR, Arora P, Garcia-Bailo B, El-Sohemy A, Karmali M and Badawi A. The relationship between metabolic syndrome components and inflammatory markers among non-diabetic Canadian adults. Journal Diabetes Metabolism. 2012; doi:10.4172/2155-6156.S2-003.

[99] Brenner DR, Arora P, Garcia-Bailo B, Wolever TMS, Morrison H, El-Sohemy A, Karmali $\mathrm{M}$, and Badawi A. Plasma vitamin D and risk of the metabolic syndrome in Canadians. Clinical Investigative Medicine. 2011;34: E377-E384.

[100] Barclay C, Procter KL, Glendenning R, Marsh P, Freeman J, Mathers N. Can type 2 diabetes be prevented in UK general practice? A lifestyle-change feasibility study [ISAIAH]. British Journal General Practice. 2008;58:541-547.

[101] Norris SL, Zhang X, Avenell A, Gregg E, Bowman B, Schmid CH, Lau J. Long-term effectiveness of weight-loss interventions in adults with pre-diabetes: a review. American Journal Preventive Medicine. 2005;28:126-139.

[102] Frost G, Leeds A, Trew G, Margara R, Dornhorst A. Insulin sensitivity in women at risk of coronary heart disease and the effect of a low glycemic diet. Metabolism 1998;47:1245-1251. 